\title{
Editorial
}

\section{¿Estamos condenados a la discordia? Violencia, intolerancia y reconciliación en Colombia}

\author{
Magda Beatriz López Cárdenas*
}

\begin{abstract}
71 número 211 de la revista Controversia indaga acerca de los vínculos entre la violencia, la intolerancia social y las dinámicas de reconciliación que se dan en las sociedades en transición. La temática de este dossier no es de un calado menor, pues la sanación de las heridas ocasionadas por la guerra, la reconstrucción del tejido social, el alcance de unos mínimos consensos para la convivencia pacífica y la no reproducción de los ciclos de violencia suelen ser atributos de la reconciliación, que se convierten, a su vez, en desafíos para aquellas sociedades que han buscado acuerdos de paz con el fin de dar solución a sus conflictos armados.
\end{abstract}

Desde esta perspectiva, la transformación de las relaciones y la (re) construcción de confianza desde las dimensiones intersubjetiva, comunitaria y política de la reconciliación, van más allá del campo de la justicia transicional por dos razones: la primera, porque la guerra es multicausal y multiactor y tiene un impacto directo e indirecto en el conjunto de la vida social, por lo cual su solución no involucra únicamente a combatientes, excombatientes y víctimas. En segundo lugar, porque dicha transformación de relaciones no se da en el vacío, sino que se encuentra condicionada por estructuras previas de la interacción y la formación social, que tienen un peso en la implementación de las políticas transicionales.

Este segundo elemento se refiere específicamente, a la violencia derivada de la fuerte diferenciación social en Colombia, arraigada en formas de discriminación como el clasismo, el racismo, la xenofobia y el sexismo,

* Coordinadora de la línea de Mediación y Reconciliación, Cinep/Programa por la Paz. 
junto con otras formas de intolerancia social, en razón de expresiones políticas o culturales. A partir de este argumento, sería muy difícil pensar en una sociedad reconciliada que redignifique a las víctimas e integre a los excombatientes, si la marginación y la persecución (o estigmatización) por causas políticas son acciones recurrentes y naturalizadas.

Los artículos contenidos en esta edición aportan elementos fundamentales para comprender la relación entre violencia, intolerancia y reconciliación, con base en cuatro nodos:

1. Desmarcar y ampliar el concepto de reconciliación. El concepto de reconciliación tiene un amplio y variado repertorio de definiciones y connotaciones que generan pocos consensos. En línea con Paul Bloomfield (2015), conviene entonces tener una definición amplia del término que recoja no solo las transformaciones institucionales y culturales, sino aquellas que no se circunscriben al ámbito transicional.

2. Ética del cuidado y reconciliación. Desde este nodo, se identifica una responsabilidad del cuidado entre semejantes y de reparar el daño infringido en perspectiva de la justicia y la dignidad de las personas.

3. La inclusión social y la construcción de ciudadanía. Los avances en materia de derechos y desarrollos institucionales hacen parte de un largo proceso histórico de luchas y conquistas sociales. Aquí la reconciliación está profundamente relacionada con el acceso a la participación y el posicionamiento en la agenda pública, por parte de grupos históricamente marginados o silenciados como las víctimas, las mujeres y los excombatientes, entre otros.

4. Pedagogía y cambio cultural. La transformación de relaciones y la (re)construcción de confianza pasan por la renovación de las 
instituciones que reproducen los imaginarios colectivos de una cultura punitiva.

Esta edición de Controversia inicia con el artículo de Mauricio García Durán, "La reconciliación: reto ético y político en el contexto colombiano", el cual introduce y desarrolla un análisis acerca de la reconciliación como campo no solo de reflexión teórica, sino como apuesta fundamental para la construcción de paz. Con este objetivo, el autor hace un balance de varios desarrollos conceptuales internacionales en materia de reconciliación, los coteja con el caso colombiano e intenta contestar simultáneamente preguntas acerca de su definición, agentes, desarrollo y temporalidad.

La reflexión de García Durán también destaca las dimensiones de la reconciliación y los debates sobre cómo esta se expresa de manera heterogénea y diferenciada durante las fases del conflicto y de la construcción de paz.

El siguiente artículo, "La paz como un esfuerzo social permanente desde la ciudadanía”, de las autoras Daniela Márquez, María Paula Lamprea y Elizabeth Molano, escudriña desde la psicología social y la sociología el fenómeno de reproducción del ciclo de violencia del conflicto en Colombia, mediante las prácticas cotidianas y la institucionalización de la cultura punitiva. El artículo da luces a la pregunta de esta edición: ¿estamos condenados a la discordia? Asimismo, plantea que, mientras el castigo se mantenga como pauta de relacionamiento y vía de hecho para hacer justicia y alcanzar la paz, "entonces estamos condenados a ser una sociedad violenta en todos los espacios de interacción social de la vida cotidiana”. Ante este escenario, las autoras proponen alternativas fundamentadas en la ética del cuidado, la justicia restaurativa y el ejercicio consciente de la ciudadanía para la inclusión y la corresponsabilidad. 
Por su parte, Diana Carolina Angulo y el grupo Semillero de Investigación en Derechos Humanos y Derecho Internacional Humanitario de la Universidad Simón Bolívar (sede Cúcuta), presentan en sus artículos algunas reflexiones sociales y desarrollos institucionales que han surgido a partir de las discriminaciones y también las reivindicaciones de las mujeres afrodescendientes y de la población LGBTI en Colombia.

Diana Angulo destaca en su texto, "Reivindicaciones interseccionales. El caso de la Red Nacional de Mujeres Afrodescendientes Kambirí", algunas reflexiones acerca de las vicisitudes que, desde una perspectiva particular y feminista propia, afrontan las afrocolombianas. Angulo plantea que, en las dinámicas de exclusión e inclusión, la acción colectiva organizada y el conocimiento y uso estratégico de instrumentos jurídicos, les ha permitido a las mujeres de este movimiento visibilizar su causa y posicionarla en la agenda pública.

En su artículo "Inclusión LGBTI en Colombia: reflexión jurídica y social”, Marlés, Numa, Jácome, Montañez y Mendoza, plantean el debate acerca de los avances y retrocesos del ordenamiento jurídico y la garantía de derechos para esta población. Mediante este ejercicio los autores plantean que, si bien los avances jurídicos en la materia han sido importantes, todavía hay una brecha en la perspectiva de seguridad jurídica para la defensa de sus derechos.

Por último, el texto de Hernán Rodríguez Vargas, "La paz difícil. El reconocimiento de la historia y los actores de paz", plantea una visión crítica acerca de cómo se ha venido configurando una narrativa hegemónica sobre los constructores de paz. Rodríguez agrega que la construcción y promoción de una cultura de paz no consisten en acciones pacificadoras, sino en una lucha por posicionar nuevas narrativas, no hegemónicas, sobre los actores que hacen la paz, las paces.

La lectura transversal de este conjunto de artículos de la Controversia número 211 propone una reflexión acerca de los retos de la reconcilia- 
ción en materia de transformación de relaciones y la (re)construcción de lazos de confianza: las iniciativas desde arriba o institucionales, en materia de justicia transicional y de derechos, no son suficientes para consolidar la paz y menos la reconciliación, sino que convergen con aquellas desde la base o comunitarias, que facilitan la activación de transformaciones culturales (Bloomfield, 2016).

Esperamos que este número suscite profundas y novedosas reflexiones. Un agradecimiento especial a los y las autoras de este número, por su esmero en estas producciones académicas, y a Mauricio Archila y Santiago Garcés por su acompañamiento e idea original.

\section{Referencias}

Bloomfield, Paul (2015). Clarificando términos: ¿Qué podemos entender por reconciliación? En Reconciliación: perspectivas y aportes conceptuales para su comprensión. Colección Papeles de Paz (vol. 10). Bogotá: CINEP/PPP.

CINEP/PPP (2014). Aprendizajes para la reconciliación: experiencias de reconciliación entre excombatientes y comunidades receptoras. Bogotá: CINEP/PPP. 